Article

\title{
Preliminary Studies on HVOF Sprayed Coatings on the Magnesium Alloys
}

\author{
Ewa Jonda ${ }^{1, *}$, Leszek Łatka ${ }^{2}$ and Grzegorz Więcław ${ }^{3}$ \\ 1 Department of Engineering Materials and Biomaterials, Silesian University of Technology, Konarskiego St. \\ 18a, 44-100 Gliwice, Poland; ewa.jonda@polsl.pl (E.J.) \\ 2 Faculty of Mechanical Engineering, Wroclaw University of Science and Technology, Łukasiewicza 7 - 9 B9 \\ St., 50 - 371 Wroclaw, Poland; leszek.latka@pwr.edu.pl (L.Ł.) \\ 3 Certech Ltd., Wilamowice, Więźniów Oświęcimia St. 38, 43 - 330 Wilamowice, Poland; \\ gwieclaw@certech.pl (G.W.) \\ * Correspondence: ewa.jonda@polsl.pl
}

Received: 16 April 2020; Accepted: 14 May 2020; Published: 15 May 2020

\begin{abstract}
In the field of modern techniques development, which improve and/or regenerate the component's surface properties, HVOF spraying of carbides or metals and its alloys is a good alternative method to other conventional surface engineering ones, including magnesium foundry alloys. Coatings manufactured by thermal spraying are used to improve the durability and life time of machine parts, both, the new and regenerated ones, by changing the surface layer properties.

In this work the results of the HVOF sprayed coatings deposited onto AZ31 magnesium alloy substrate. The feeding material was composite powder $\mathrm{Cr}_{3} \mathrm{C}_{2}-\mathrm{NiCr}$. The coatings were investigated in terms of their microstructure and selected mechanical properties. For structure examinations the microscopy studies (light and scanning ones) were used as well as phase composition analysis. In case of mechanical properties, the wear resistance was determined also microhardness have been measured.
\end{abstract}

Keywords: HVOF spraying; AZ31 substrate; microstructure; microhardness; wear resistance

\section{Introduction}

The development of technology forces the demand for functional and technological surfaces that are increasingly more perfect. Knowledge of techniques for the production of surface layers and coatings allows their proper selection for specific operating conditions. One of the many methods of extending the life of machine parts, both new and regenerated, and as a result of increasing their reliability and operational durability is the application of coatings by means of thermal spraying technology, which consists in producing metal, carbide, ceramic and composite coatings on a properly prepared substrate with almost any chemical and phase composition. Spraying is mainly used to make coatings with high resistance to abrasion, protection against high temperature and corrosion [1-4].

One of the most commonly used methods is supersonic thermal spraying HVOF (High Velocity Oxygen Fuel), which allows the production of coatings with special properties, among others: low oxidation, very low porosity and high adhesion $[5,6]$. These coatings are free of oxides, which is often required due to their operational properties, and is difficult to obtain in other thermal spraying methods. The main materials used in thermal spraying HVOF are chromium carbide or tungsten carbide particles in a metal alloy matrix consisting of various combinations of $\mathrm{Cr}, \mathrm{Ni}$ or $\mathrm{Co}$. The one of the most common coating is $\mathrm{Cr}_{3} \mathrm{C}_{2} / \mathrm{NiCr}$ because chromium carbide coating with a ductile nickel binder is very often used in industrial environment to protect against abrasive wear and corrosion. 
So, the main goal to achieve by coating with cermet is to increase wear resistance of parts and resistance to oxidation. It could also work as an alternative to hard chrome plating [7-11].

For several years, there has been a visible interest in non - ferrous alloys, including magnesium alloys, which are the subject of research in many research and development centers, as well as in major manufacturers of machine - building, chemical, energy, textile, electronic, office, aeronautical, in particular the automotive, shipbuilding, aviation and sports industries. The growing trends in the production of magnesium alloys indicate an increased need for their use in the global construction industry, and thus these alloys will become one of the most commonly used construction materials of our century, so it is extremely important to maintain a high pace of research on the problems of light alloys $[12,13]$.

\section{Materials and Methods}

\subsection{Coatings Deposition}

Investigations were carried out on samples from the AZ31 magnesium alloy substrate (Institute of Non - Ferrous Metals in Gliwice, Skawina, Poland), with $5 \mathrm{~mm}$ in the thickness. The chemical composition of the alloy is shown in Table 1.

Table 1. The chemical composition of the AZ31 magnesium alloy $[14,15]$.

\begin{tabular}{lllllll}
\hline $\begin{array}{c}\text { Elements, } \\
\text { in wt. \% }\end{array}$ & $\mathrm{Mn}$ & $\mathrm{Zn}$ & $\mathrm{Al}$ & $\mathrm{Ca}$ & $\mathrm{Cu}$ & $\mathrm{Mg}$ \\
\hline AZ31 & 0.17 & 1 & 3 & 0.04 & 0.05 & balance \\
\hline
\end{tabular}

The feedstock material for the coatings manufacturing was $\mathrm{Cr}_{3} \mathrm{C}_{2}-25 \mathrm{wt} \% \mathrm{NiCr}$. The powder particles size distribution was in the range $-30+5 \mu \mathrm{m}$. It was a commercially available powder (Amperit 588.059 - Höganäs). The morphology of initial powder is presented in Figure 1.

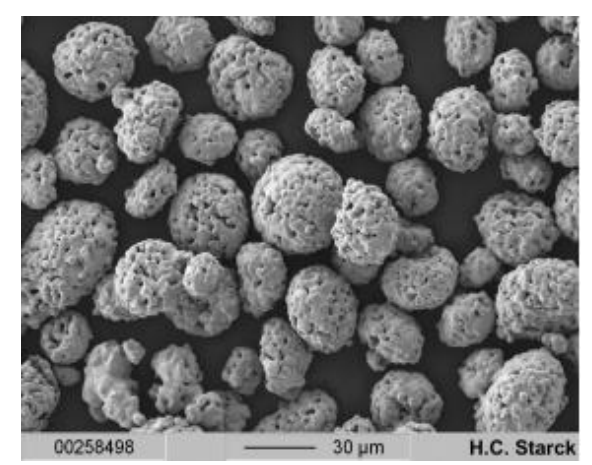

Figure 1. SEM (secondary electrons) micrographs of the $\mathrm{Cr}_{3} \mathrm{C}_{2}-\mathrm{NiCr}$ powder [16].

The chemical composition of the feedstock powder, which was used in coatings manufacturing process is given in Table 2 .

Table 2. The chemical composition of the chromium carbide powder $\mathrm{Cr}_{3} \mathrm{C}_{2}-\mathrm{NiCr}$ [16].

\begin{tabular}{cc}
\hline Element & in wt. \% \\
\hline Chromium & $66-73$ \\
\hline Carbide & $9-11$ \\
\hline Fe & $<0.5$ \\
\hline Nickiel & $15-22$ \\
\hline Oxygen & $<0.6$ \\
\hline
\end{tabular}

Before spraying all samples were sand blasted with corundum to get a surface roughness in the range of Ra equal to $17 \mu \mathrm{m}$. Then the substrates were coated by the coating material using a $\mathrm{C}$ - CJS 
spray system Thermico. The thermal spraying was made by CERTECH Company, Wilamowice, Poland. Kerosene and oxygen were used as the fuel gases with flow rates of $401 / \mathrm{min}$ and $350 \mathrm{l} / \mathrm{min}$, respectively, whereas nitrogen was used as the carrier gas with a flow rate of $10 \mathrm{l} / \mathrm{min}$. The powder feed rate was fixed at $25 \mathrm{~g} / \mathrm{min}$. The spray distance was equal to $280 \mathrm{~mm}$.

\subsection{Coatings Characterization}

Samples for metallographic observations were prepared by standard grinding and polishing techniques. Microstructure observations were made using scanning electron microscope, SEM (Supra 35, Zeiss, Oberkochen, Germany) using secondary electron and backscattered detectors. The chemical composition was analyzed by EDS. The light microscopy (Axio Obsever, Zeiss, Oberkochen, Germany) was used to determine coatings thickness measured on random places. The average from 10 measurements was statistically calculated. In order to determine the phase composition of the $\mathrm{Cr}_{3} \mathrm{C}_{2}-\mathrm{NiCr}$ coating, X-ray diffraction, XRD, tests were carried out. XRD investigations of sprayed coatings were done by $X$ - ray diffractometer X'Pert Pro MPD by Panalytical (Almelo, the Netherlands) apparatus with a copper anode lamp $(\lambda K \alpha=0.154 \mathrm{~nm})$ (Panalytical, Almelo, the Netherlands) as well as a PIXcel 3D detector (Panalytical, Almelo, the Netherlands) on the diffracted beam axis. The diffraction lines were recorded in the Bragg Brentano geometry in the angular scope of $15-90^{\circ}$, with the step of $0.03^{\circ}$ and the step time of $0.8 \mathrm{~s}$. The analysis of the obtained diffraction patterns was made in the Panalytical High Score Plus software (Version 3.0e), containing a dedicated flat - file base of PAN - ICSD phase identification. The testing of mechanical properties was started by measurements of coating adhesion. Microhardness distribution of coated specimen from the surface to substrate was estimated using the Vickers hardness test method with a force equal to $2.94 \mathrm{~N}$ (HV0.3). The tests were performed along lines perpendicular to specimen surfaces, along the run face axis. The wear resistance of the manufactured coating was analyzed using the "pin - on -disc" tribological test. As a counter body, a $6 \mathrm{~mm}$ diameter ball of zirconium oxide, $\mathrm{ZrO}_{2}$ was used. During the test, the friction coefficient was recorded. The test was performed at room temperature using the testing conditions given in Table 3 . The wear track dimensions after tests were measured by a Sutronic 25 - Taylor Hobson profilometer (Taylor Hobson Ltd., Leicester, England), and the topography was analyzed using an SEM to determine mechanism of the wear.

Table 3. Testing conditions of the "pin - on - disc" method.

\begin{tabular}{cc}
\hline Parameter & Value \\
\hline Load, $\mathrm{N}$ & 5 \\
\hline Linear speed, $\mathrm{cm} / \mathrm{s}$ & 20 \\
\hline Distance, $\mathrm{m}$ & 500 \\
\hline Ball diameter, $\mathrm{mm}$ & 6 \\
\hline
\end{tabular}

\section{Results}

\subsection{Coatings Microstructure}

The cross section micrographs show, that obtained coatings are characterized by homogeneous and dense structure. It is reveal that coating is well bonded to the substrate, there is no discontinuity at the interface. The porosity is low and the average pore size is also small. It could be observed, that the $\mathrm{Cr}_{3} \mathrm{C}_{2}$ particles are surrounded by the $\mathrm{Ni}$ - $\mathrm{Cr}$ matrix, which well adhered to the carbide particles. Figure 2 shows the cross - section of the manufactured coating. 

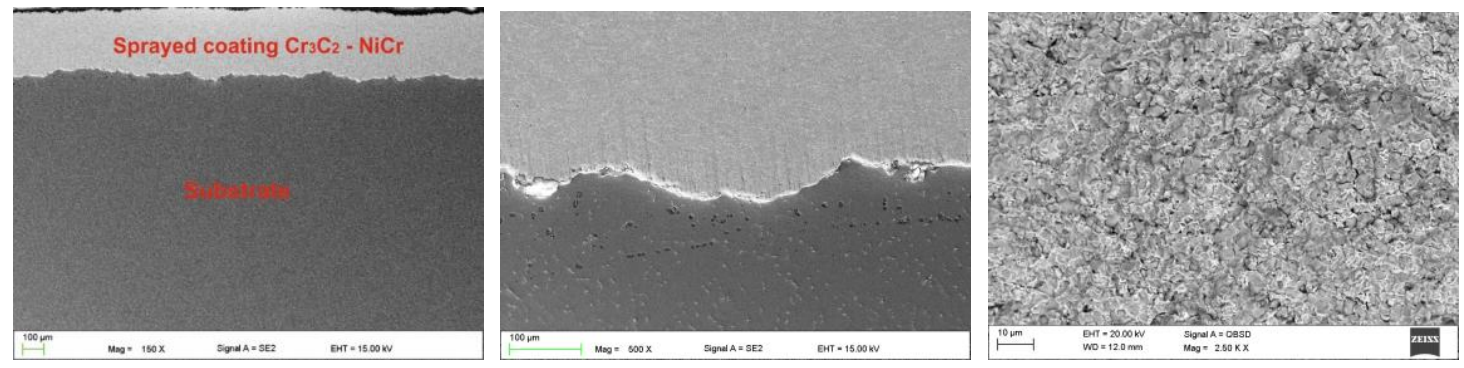

Figure 2. Cross - section of manufactured coating: (a) mag. 150×, (b) mag. 500× and (c), mag. 2500×.

The phase composition of manufactured coating is given in Figure 3. As it could be seen, there are two phases, namely $\mathrm{Cr}_{3} \mathrm{C}_{2}$ and $\mathrm{CrNi}_{3}$. There are also some indications of $\mathrm{C}$. For qualitative and quantitative analysis the RIR method [17] was used. There is about $65 \%$ of the $\mathrm{Cr}_{3} \mathrm{C}_{2}$ phase and around $35 \%$ of the $\mathrm{CrNi}_{3}$ phase. Similar phase composition could be found e.g., in [18,19].

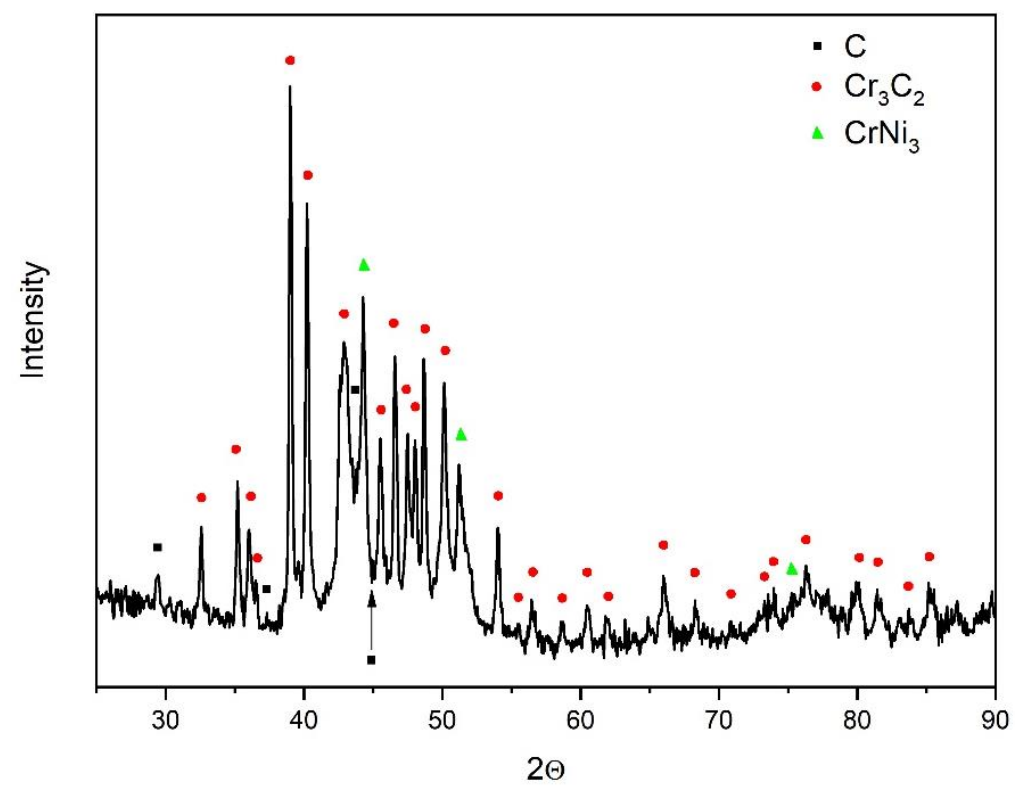

Figure 3. XRD pattern of the manufactured coating.

\subsection{Microhardness}

Based on the results of the investigations, it was found that the microhardness of the coating increases, and the maximum value is obtained as $790 \mathrm{HV} 0.3$, while the minimum hardness is about 180 HV0.3, which means that the produced coating has increased in hardness compared to the substrate (AZ31) by about 338\% (Figure 4.). An increase in temperature during the HVOF spraying process causes oxidation and the formation of a protective layer on the surface of the coating which does not affect its hardness. On the basis of XRD (Figure 3) analysis it was found that the existence of $\mathrm{Cr}_{3} \mathrm{C}_{2}$ phase provides an increase in hardness of the $\mathrm{Cr}_{3} \mathrm{C}_{2}-\mathrm{NiCr}$ coating. It was reported in [20] that due to very high speed, powder particles can melt and dissolve carbides to varying degrees. Besides, the particles are not exactly the same size, so small particles melt completely and larger particles do not melt completely. The wide size range of powder particles causes some particles to overheat significantly while others are insufficiently melted, which may be the cause of increased porosity and reduced coating hardness. Also, an increase in the size of the carbide causes an increase in the porosity of the coating [20]. 


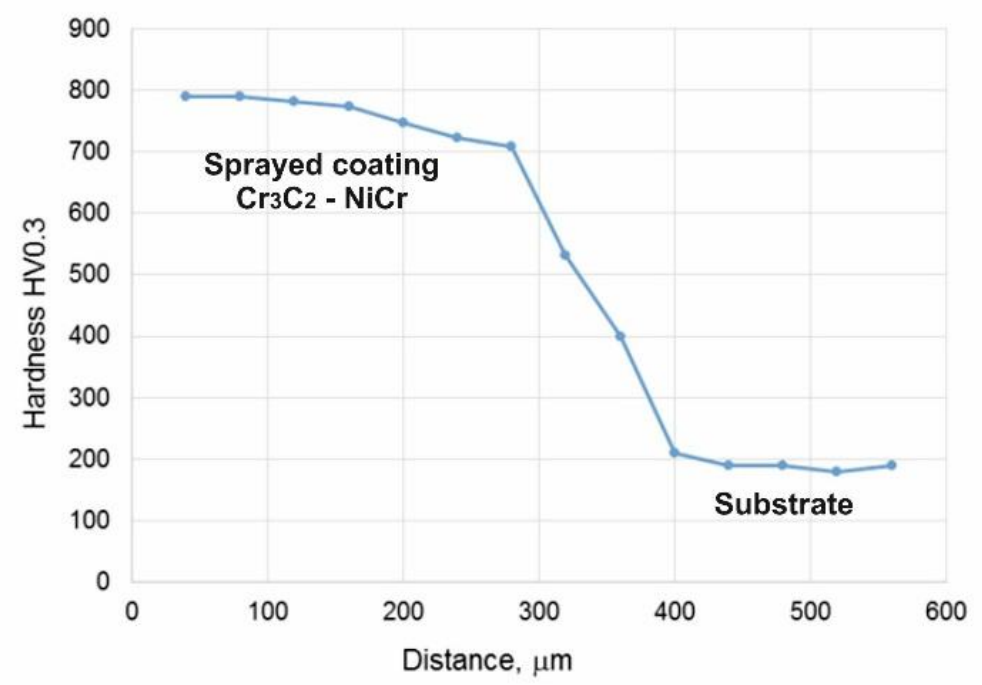

Figure 4. Hardness distribution of coated sample from the surface to substrate.

\subsection{Wear Resistance}

The results of dry sliding wear test show, that manufactured coating exhibit good resistance for wear. The volumetric wear of investigated coatings was equal to $13.88 \pm 3.11 \cdot 10^{-6} \mathrm{~mm}^{3} /(\mathrm{N}-\mathrm{m})$. The friction coefficient was equal to $0.6 \pm 0.03$. Similar values could be found in the literature $[21,22]$ The typical wear trace is given in Figure 5.

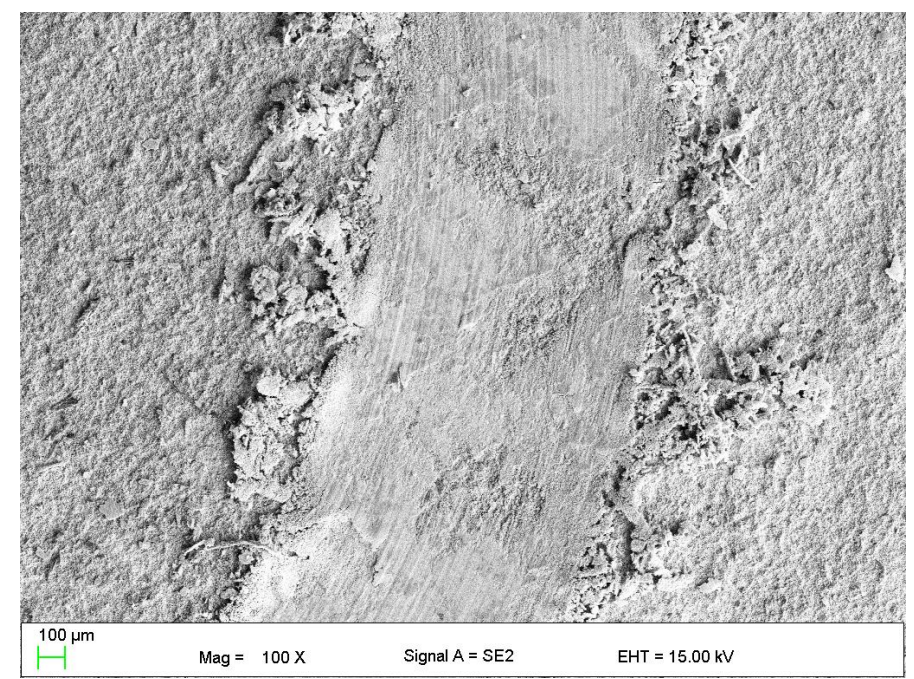

Figure 5. Wear tracks of $\mathrm{Cr}_{3} \mathrm{C}_{2}-\mathrm{NiCr}$ coatings, mag. 100x.

During microscopic observation of wear tracks it was found, that the dominant mechanism of wear is a classic adhesive one. On the worn surface it could be observed such phenomena as decohesion areas, oxidation wear (because of increasing temperature during tests), plastic and fatigue wear and areas of smearing of the debris from counter - body $\left(\mathrm{ZrO}_{2}\right.$ ball). Similar wear mechanism could be found e.g., in [23]. Some of these phenomena are presented in Figure 6. 
a)

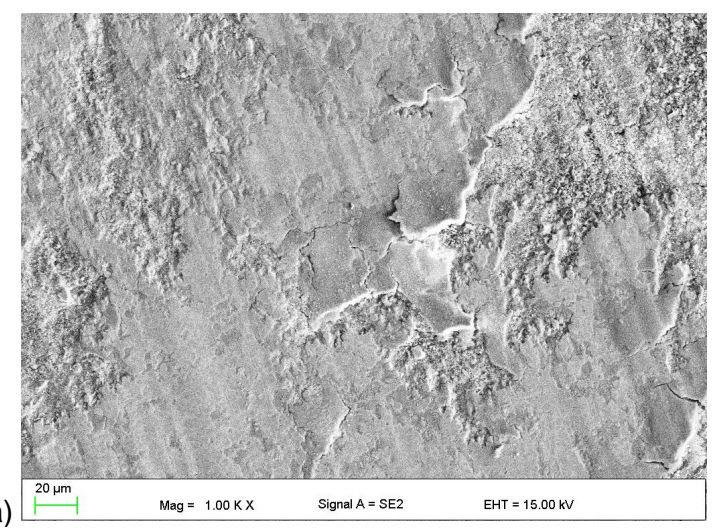

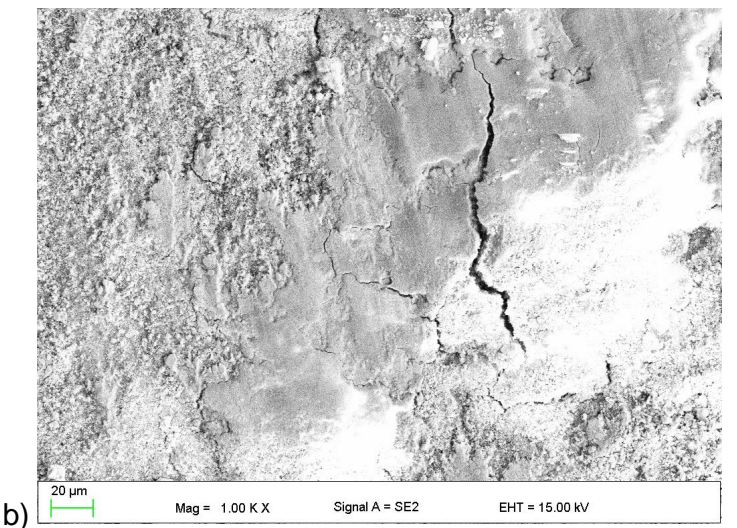

Figure 6. Different wear mechanism of $\mathrm{Cr}_{3} \mathrm{C}_{2}-\mathrm{NiCr}$ coating: (a) low cycle fatigue, and (b) spallation and cracks.

\section{Conclusions}

In this premilinary studies, the $\mathrm{Cr}_{3} \mathrm{C}_{2}-\mathrm{NiCr}$ coatings have been manufactured by $\mathrm{HVOF}$ method on the magnesium alloy AZ31. Based on the carried out investigations, the following conclusions can be drawn:

- The obtained coating is characterized by homogeneous and dense structure, also no cracks or discontinuities were found on the surface of the produced $\mathrm{Cr}_{3} \mathrm{C}_{2}-\mathrm{NiCr}$ coating.

- The thickness of the manufactured coating was about $300 \pm 15 \mu \mathrm{m}$.

- Measurements of the microhardness distribution in the sprayed coating indicate an increase up to $790 \mathrm{HV} 0.3$ (substrate material was equal to $180 \mathrm{HV} 0.3$ ).

- In the sprayed coatings are two main phases, namely $\mathrm{Cr}_{3} \mathrm{C}_{2}$ and $\mathrm{CrNi}_{3}$.

- The dominant mechanism of wear is a classic adhesive one.

Author Contributions: E.J. conceived and designed the experiments; G.W. performed the thermal spraying coating; L.Ł. analyzed the data; E.J. and L.Ł. wrote the paper-review and editing.

Funding: These investigations were financed by the Ministry of Science and Higher Education of Poland, Grant DEC - 2019/03/X/ST5/00830. The authors are thankful to Drs. P. Nuckowski and W. Pakieła (Silesian University of Technology, Gliwice, Poland) for help with investigations.

Conflicts of Interest: The authors declare no conflicts of interest.

\section{References}

1. Davis, J.R. (ed.), Handbook of thermal spray technology. ASM International. 2004.

2. Fauchais, P.L.; Heberlein, J.V.R.; Boulos, M.I. Thermal spray fundamentals: From powder to part. Springer US, New York, 2014.

3. Pawłowski, L. The science and engineering of thermal spray coatings, $2^{\text {nd }}$ ed. Wiley, Chichester, UK, 2008.

4. Gan, J.A., Berndt, C.C., Nanocomposite coatings: Thermal spray processing, microstructure and performance. International Materials Reviews. 2015, 60, 195-244.

5. Houdkova' S., Kasparova' M., and Zahalka, F., The influence of spraying angle on properties of HVOF sprayed hardmetal coatings. Journal of Thermal Spray Technology. 2010, 19, 893-901.

6. Poirier, D., Legoux, J.G., and Lima, R.S., Engineering HVOF - sprayed $\mathrm{Cr}_{3} \mathrm{C}_{2}-\mathrm{NiCr}$ coatings: The effect of particle morphology and spraying parameters on the microstructure, properties, and high temperature wear performance. J. Therm. Spray Technology. 2013, 22, 280-289.

7. Guilemany, J.M., Espallargas, N., Suegama, P.H., Benedetti, A.V., Comparative study of $\mathrm{Cr}_{3} \mathrm{C}_{2}-\mathrm{NiCr}$ coatings obtained by HVOF and hard chromium coatings. Corros. Sci. 2006, 48, 2998-3013.

8. Lin, L.; Li, G.-L.; Wang, H.-D.; Kang, J.-J.; Xu, Z.-L.; Wang, H.-J. Structure and wear behavior of nicr-cr3c2 coatings sprayed by supersonic plasma spraying and high velocity oxy-fuel technologies. Appl. Surf. Sci. 2015, 356, 383-390. 
9. Karaoglanli, A.C., Oge, M., Doleker, K.M., Hotamis, M., Comparison of tribological properties of HVOF sprayed coatings with different composition. Surf. Coat. Technology. 2017, 318, 299-308.

10. Sahraoui, T., Fenineche, N.E., Montavon, G., Coddet Ch., Structure and wear behavior of HVOF sprayed $\mathrm{Cr}_{3} \mathrm{C}_{2}-\mathrm{NiCr}$ and WC - Co coatings. Mater. Des. 2003, 24, 309-313.

11. Bobzin, K., Zhao, L., Öte, M., Königstein, T., Steeger, M., Impact wear of an HVOF-sprayed $\mathrm{Cr}_{3} \mathrm{C}_{2}-\mathrm{NiCr}$ coating. Int. J. Refract. Met. Hard Materials. 2018, 70, 191-196.

12. Mordike, B.; Ebert, T. Magnesium: Properties-applications-potential. Mater. Sci. Eng. : A 2001, 302, 3745.

13. Dobrzański, L. .A., Tański, T., Dobrzańska - Danikiewicz, A.D., Król, M., Malara, S., Domagała - Dubiel, J., Structure and properties of Mg-Al-Zn alloys. Open Access Libr. 2012, 5/11, 11-25.

14. Yang, Z., Li, J.P., Zhang, J.X., Larimer, G.W., Robson, J., Review and research and development of magnesium alloys. Acta Metall. Sinica. 2008, 5, 313-328.

15. Zagórski, I., Pieśko, P., Comparative investigation on surface roughness of selected magnesium alloys after milling with a full - carbide tool and PKD Prog. Sci. Technol. 2011, 8, 53-58.

16. Available online: www.hoganas.com/en (access on 15 May 2020).

17. Prevey, P.S., X-ray diffraction characterization of crystallinity and phase composition in plasma-sprayed hydroxyapatite coatings, Journal of Thermal Spray Technology. 2000, 9, 369-376.

18. Murthy, J.K.N., Venkataraman, Abrasive wear behavior of $\mathrm{WC}-\mathrm{CoCr}$ and $\mathrm{Cr}_{3} \mathrm{C}_{2}-20(\mathrm{NiCr})$ deposited by HVOF and detonation spray processes. Surf. Coat. Technol. 2006, 200, 2642-2652.

19. Matthews, S., James, B., Hyland, The role of microstructure in the mechanism of high velocity erosion of Cr3C2 - NiCr thermal spray coatings: Part 1 - As - sprayed coatings. Surf. Coat. Technol. 2009, 203, 10861093.

20. Hajare, A.S.; Gogteb, C.L.; Comparative study of wear behavior of Thermal Spray HVOF coating on 304 SS. Mater. Today: Proceedings. 2018, 5, 6924-6933.

21. Sidhu, H.S.; Sidhu, B.S.; Prakash, S., Wear characteristics of $\mathrm{Cr}_{3} \mathrm{C}_{2}-\mathrm{NiCr}$ and WC - Co coatings deposited by LPG fueled HVOF. Tribol. Int. 2010, 43, 887-890.

22. Gariboldi, E., Rovatti, L., Lecis, N., Mondora, L., Mondora, G.A., Tribological and mechanical behavior of $\mathrm{Cr}_{3} \mathrm{C}_{2}-\mathrm{NiCr}$ thermally sprayed coatings after prolonged aging. Surf. Coat. Technol. 2016, 305, 83-92.

23. Bolelli, G., Berger, L.M., Borner, T., Koivuluoto, H., Matikainen, V., Lusvarghi, L., Lyphout, D., Markocsan, N., Nylen, P., Sassetelli, P., Trache, R., Vouristo, P., Sliding and abrasive wear behavior of HVOF- and HVAF-sprayed $\mathrm{Cr}_{3} \mathrm{C}_{2}$ - NiCr hard metal coatings. Wear 2016, 358-359, 32-50.

(C) 2020 by the authors. Submitted for possible open access publication under the terms and conditions of the Creative Commons Attribution (CC BY) license (http://creativecommons.org/licenses/by/4.0/). 